\title{
Electrophysical characteristics of an activated adsorbent from humic acid
}

Ermagambet B.T. ${ }^{1}$, Kasenov B.K. ${ }^{2}$, Kazankapova M.K. ${ }^{1}$, Kassenova Zh.M. ${ }^{1}$, Nurgaliev N.U. ${ }^{1}$, Kuanyshbekov E.E. ${ }^{2}$

${ }^{1}$ TOO "Institute of Coal Chemistry and Technology", Nur-Sultan, Kazakhstan, coaltech@bk.ru

${ }^{2}$ Chemical and Metallurgical Institute named after J. Abishev, Karaganda, Kazakhstan

doi: 10.36291/HIT.2019.ermagambet.113

Electrophysical properties are the main indicator of carbon materials used in electrothermal processes, as well as for the manufacture of superconducting materials, capacitors and fuel cells from them [1]. Measurements of electrophysical properties were carried out according to the method [2].

The electrophysical characteristics of an activated adsorbent from humic acid based on coal from the Maykuben deposit (Kazakhstan) were investigated. Porous-carbon material was obtained by carbonization and activation in argon and water vapor. The study of electrophysical properties (dielectric constant $(\varepsilon)$, electrical resistance $(R)$ ) was carried out by measuring the electrical intensity of the samples on a LCR-800 serial device (Taiwan) at an operating frequency of $1 \mathrm{kHz}, 5 \mathrm{kHz}$ and $10 \mathrm{kHz}$ continuously in dry air in thermostatic mode with exposure time at each fixed temperature (293-483 K). Based on the data obtained, the band gap $(\Delta \mathrm{E})$ of the samples was calculated.

When comparing the electrophysical characteristics of the activated adsorbent from humic acid at various frequencies, it was found that a change in frequency from $1 \mathrm{kHz}$ to $10 \mathrm{kHz}$ does not strongly affect the value of electrical resistance in the range 293-483 K. For example, the lgR values at $293 \mathrm{~K}$ and at $1 \mathrm{kHz}$ are 4,03 ohms, at $5 \mathrm{kHz}-3.99$ ohms and at $10 \mathrm{kHz}-3.97 \mathrm{ohms}$, and at $483 \mathrm{~K}$ and at $1 \mathrm{kHz}-2.93 \mathrm{ohms}$, at $5 \mathrm{kHz}-2.92 \mathrm{ohms}$ and at $10 \mathrm{kHz}-2,92$ ohms. The values of dielectric constant $(\varepsilon)$ at various frequencies varies with decreasing transition from $1 \mathrm{kHz}$ to $10 \mathrm{kHz}$. For example, the value of $\varepsilon$ at 293 $\mathrm{K}$ and $1 \mathrm{kHz}$ is $1.891 \cdot 10^{6}$, at $293 \mathrm{~K}$ and $5 \mathrm{kHz}-3.295 \cdot 10^{5}$, at $293 \mathrm{~K}$ and $10 \mathrm{kHz}-1.462$. $10^{5}$, and at $483 \mathrm{~K}$ and $1 \mathrm{kHz}-4.336 \cdot 10^{8}$, at $483 \mathrm{~K}$ and $5 \mathrm{kHz}-5.474 \cdot 10^{7}$ and at $483 \mathrm{~K}$ and $10 \mathrm{kHz}-2.013 \cdot 10^{7}$. The above data show that the maximum values of $\varepsilon$ are obtained by measuring a frequency of $1 \mathrm{kHz}$.

Acknowledgements. This work was carried out as part of the scientific and technical program No. IRN BR05236359 "Scientific and technological support for coal processing and production of high-value coal products" and project No. IRN AP05130707 on the theme "Development of technology and creation of the production of carbon nanocomposite materials based on domestic mineral raw materials for cleaning the gas phase and wastewater ", funded by the Science Committee of the Ministry of Education and Science of the Republic of Kazakhstan.

References

1. Yermagambet B.T. et al. // Industry of Kazakhstan. 2019. 1(105):70-72.

2. Zhumadilov E.K. et al. // Bulletin of the NAS of the Republic of Kazakhstan. 2004. 5:114-118. 